\title{
T2d Stage Finding
}

National Cancer Institute

\section{Source}

National Cancer Institute. T2d Stage Finding. NCI Thesaurus. Code C148411.

A TNM stage finding term that refers to choroidal and ciliary body melanoma or conjunctival melanoma TNM staging. For choroidal and ciliary body melanoma it means tumor size category 2 with ciliary body involvement and extraocular extension $5 \mathrm{~mm}$ or less in largest diameter. For conjunctival melanoma it means caruncular tumor, and more than 1 quadrant of the nonbulbar conjunctiva involved. (from AJCC 8th Ed.) 